\title{
Avaliação do Plano de Ação Implementado pelo Serviço Médico de uma Unidade de Referência em Cuidados Paliativos Oncológicos frente à Pandemia de Covid-19
}

doi: https://doi.org/10.32635/2176-9745.RBC.2020v66nTemaAtual.1158

\author{
Evaluation of the Action plan Implemented by the Medical Service of a Referral Unit in Oncology Palliative Care because of \\ the COVID-19 Pandemic \\ Evaluación del Plan de Acción Implementado por el Servicio Médico de una Unidad de Referencia en Cuidados Paliativos \\ de Oncología ante la Pandemia de Covid-19
}

Simone Garruth dos Santos Machado Sampaio'; Andréa Marins Dias²; Renata de Freitas ${ }^{3}$

\section{INTRODUÇÃO}

Inúmeros foram os impactos que a pandemia da doença pelo coronavírus 2019 (coronavirus disease 2019-Covid-19) trouxe aos serviços de saúde e seus usuários. Por um lado, as adaptaçôes necessárias para o atendimento seguro dos casos suspeitos de Covid-19; por outro, a necessidade de prosseguir com o atendimento aos pacientes em todas as suas demandas ${ }^{1}$. Isso motivou a elaboração e a implementação de um plano de ação para enfrentamento à pandemia pela Covid-19 por parte do Serviço Médico da Unidade de Cuidados Paliativos do Hospital do Câncer IV (HC IV) do Instituto Nacional de Câncer José Alencar Gomes da Silva (INCA), especializado e de referência nacional em cuidados paliativos oncológicos ${ }^{2}$.

A expectativa inicial da equipe, motivada por notícias de outros países, seria de cenário de guerra, com hospital lotado, sem capacidade de manter o atendimento a outras demandas que não a Covid-19. A equipe se instrumentalizou, se reinventou e fez constantes ajustes para que a expectativa inicial não se concretizasse.

\section{DESENVOLVIMENTO}

A avaliação formal deste plano de ação se faz necessária. Uma análise inicial subjetiva acrescida de dados objetivos descritivos dos três primeiros meses (abril a junho de 2020) foi realizada e será seguida por informaçôes mais detalhadas.

O Serviço é composto por 19 médicos. Oito deles tiveram Covid-19 confirmada. Um dos temores iniciais era o afastamento simultâneo de vários profissionais, o que não ocorreu, favorecendo o desenrolar da estratégia definida.
O primeiro paciente da síndrome respiratória aguda grave do coronavírus 2 (severe acute respiratory syndrome coronavirus 2 - Sars-CoV-2) internou na unidade em $1^{\circ}$ de abril de 2020 por transferência de outra unidade do INCA. Na ocasião, o plano de ação já havia sido divulgado internamente e toda equipe já havia sido treinada.

Em relação à equipe médica, o processo de atendimento da unidade que sofreu maior impacto no período foi o Serviço de Pronto Atendimento (SPA). Sendo um setor que atende à demanda espontânea e imprevisível, inúmeros ajustes foram realizados na proposta inicial ao longo do tempo. O fluxograma com orientaçóes para conduta medicamentosa foi modificado à medida que novos conhecimentos técnicos foram descobertos.

O SPA realizou 647 consultas médicas no período estudado. Destes, $327(50,1 \%)$ necessitaram ser internados, sendo 69 por suspeita de Covid-19. Vale informar que a proporção de internação por atendimento no SPA foi de $49 \%$ em janeiro de 2020.

Era imprescindível identificar os casos suspeitos de infecção e de portadores assintomáticos (pacientes e familiares) antes que adentrassem ao setor, evitando disseminação intra-hospitalar do vírus. Uma pré-triagem para identificação de suspeição clínica ou epidemiológica ainda fora do setor foi instituída. Uma sala de isolamento exclusiva para atendimento a esses pacientes foi providenciada. No mesmo local, puderam também receber os primeiros cuidados ou aguardar por eventual internação hospitalar.

Em paralelo à preocupação da disseminação intra-hospitalar de Covid-19, estava o olhar atento para as consequências de uma internação definida como suspeita para paciente e familiares. A partir das literaturas nacional

\footnotetext{
${ }^{1}$ Doutora. Médica. Unidade de Cuidados Paliativos do Hospital do Câncer IV (HC IV). Instituto Nacional de Câncer José Alencar Gomes da Silva (INCA). Rio de Janeiro (RJ), Brasil. Orcid iD: https://orcid.org/0000-0001-5537-7399

2 Especialista. Médica. Unidade de Cuidados Paliativos HC IV/INCA. Rio de Janeiro (RJ), Brasil. Orcid iD: https://orcid.org/0000-0003-1513-6640

${ }^{3}$ Mestranda. Médica. Unidade de Cuidados Paliativos HC IV/INCA. Rio de Janeiro (RJ), Brasil. Orcid iD: https://orcid.org/0000-0001-7285-8768

Endereço para correspondência: Simone Garruth dos Santos Machado Sampaio. Rua Visconde de Santa Isabel, 274 - Vila Isabel. Rio de Janeiro (RJ), Brasil. CEP 20560-121. E-mail: simonegarruth@gmail.com
} 
e internacional e de orientaçóes governamentais ${ }^{3-6}$, foram criados critérios para definição de caso suspeito específicos à população atendida pela unidade: ser contactante de caso suspeito ou confirmado há menos de 14 dias e/ou febre sem foco definido e/ou sintomas respiratórios não explicados pela doença oncológica e/ou síndrome gripal/ sintomas sugestivos de Covid-19 e/ou imagem radiológica sugestiva.

Foi realizada uma análise inicial incluindo todos os pacientes internados pelo SPA entre $1^{\circ}$ de abril a 30 de junho de 2020. Os pacientes que preencheram os critérios de suspeição foram submetidos à coleta de swab naso e orofaríngeo para pesquisa de Sars-CoV-2 por Reverse Transcription - Polymerase Chain Reaction (RT-PCR). Resultado de RT-PCR positivo foi o critério utilizado como padrão-ouro para definição de caso de Covid-19. Foram considerados falso-negativos os casos diagnosticados em até dez dias após a data de admissão na internação. A acurácia desse critério foi de $88 \%$.

O setor da internação hospitalar (IH) destinado a pacientes suspeitos e confirmados por Covid-19 também precisou se reinventar. Em uma unidade onde a presença de acompanhante é estimulada e de grande valia sob vários aspectos, lidar com restrição de visita a pacientes e ausência de acompanhantes em pacientes com Covid-19 foi um desafio. A comunicação e o acolhimento aos familiares tiveram imenso apoio da equipe de psicologia.

Entre $1^{\circ}$ de abril e 30 de junho de 2020, 134 pacientes estiveram internados com quadro suspeito e coletaram $s w a b$ naso e orofaríngeo. Outros quatro coletaram como pré-operatório. Destes, 81 apresentaram resultado de RT-PCR positivo para Sars-CoV-2, 49 negativo e oito foram indeterminados.

Analisando os 81 casos confirmados, o período com maior número de casos foi entre 16 de abril e 31 de maio de 2020, englobando 64 (79\%) dos casos. Em relação à origem do paciente, 34 (42\%) foram provenientes de transferência hospitalar de outra unidade do instituto, 33 (41\%) internaram pelo SPA, dois (2\%) pelo ambulatório e 12 (15\%) internaram sem suspeição de Covid-19 e apresentaram quadro clínico sugestivo ao longo da internação na unidade. $\mathrm{O}$ tempo entre o início dos sintomas e a admissão na IH variou de zero a 29 dias, mediana de três dias. A internação perdurou por 0 a 69 dias, com mediana de seis dias. Sobre o desfecho, 69 (85\%) evoluíram a óbito e $12(15 \%)$ receberam alta hospitalar. Vale sinalizar que a mortalidade média na IH em 2019 foi de 64\%.

O subgrupo que iniciou sintoma durante a internação merece destaque, uma vez que estavam alocados em área não destinada à Covid-19. Destes 12 pacientes, seis iniciaram sintoma em até seis dias ${ }^{7}$ após a admissão - pode ter havido falha na triagem; dois haviam sido recém-transferidos de outra unidade sem sinalizaçáo de suspeição; e quatro com início de sintoma acima de oito dias internados, que devem corresponder ao caso nosocomial. Foi seguido o protocolo para caso nosocomial orientado pela Comissão de Controle de Infecção Hospitalar.

Pela equipe médica do ambulatório, foram realizados 643 teleatendimentos e 550 atendimentos presenciais no período. E, entre os pacientes acompanhados pela assistência domiciliar, 109 consultas médicas presenciais e 189 teleatendimentos. A avaliação subjetiva dos teleatendimentos foi positiva, com aparente controle de sintoma eficiente.

\section{CONCLUSÃO}

Em meio a dúvidas e incertezas, o Serviço se reorganizou e conseguiu apresentar um bom trabalho e três grandes legados foram deixados pela pandemia: telemedicina, comunicação e fortalecimento. A possibilidade de usufruir da telemedicina de forma sistemática e segura foi um grande aliado no controle de sintomas. A comunicação fluida entre os profissionais, especialmente entre os processos de atendimento, foi vital para o sucesso do plano elaborado - seja para os casos de Covid-19, seja para os sintomas do próprio câncer. A equipe ficou mais fortalecida e unida depois de "trocar a roda do carro com ele andando" como diz o ditado popular.

\section{CONTRIBUIÇÕES}

Simone Garruth dos Santos Machado Sampaio participou da concepção e redação do manuscrito. Andrea Marins Dias e Renata de Freitas participaram da concepção e revisão com contribuição intelectual. Todas as autoras aprovaram a versão final publicada.

\section{AGRADECIMENTOS}

Às enfermeiras Alessandra Zanei Borsatto e Elisa Maffioletti Furtunato Leocádio Esteves pela parceria e auxílio no monitoramento dos casos.

\section{DECLARAÇÃO DE CONFLITO DE INTERESSES}

Nada a declarar.

\section{FONTES DE FINANCIAMENTO}

Não há.

\section{REFERÊNCIAS}

1. Academia Nacional de Cuidados Paliativos (BR). Posicionamento da Academia Nacional de Cuidados 
Paliativos sobre COVID-19 [Internet]. São Paulo: ANCP; [2020] [acesso 2020 jun 29]. Disponível em: https://www.dropbox.com/s/g77qi6xk2jc8rky/FINAL ANCP_Ebook_cuidados_COVID-19.pdf?dl=0

2. Sampaio SGSM, Dias AM, Freitas R. Orientaçóes do serviço médico de uma unidade de referência em cuidados paliativos oncológicos frente à pandemia de Covid-19. Rev Bras Cancerol. 2020;66(TemaAtual):e-1058. doi: https://doi.org/10.32635/2176-9745. RBC.2020v66nTemaAtual.1058

3. Klompas M. Coronavirus disease 2019 (COVID-19): protecting hospitals from the invisible. Ann Intern Med. 2020;172(9):619-620. doi: https://doi.org/10.7326/ M20-0751

4. Secretaria de Atenção Primária à Saude. Protocolo de manejo clínico do coronavirus (COVID-19) na atenção primária à saúde [Internet]. Brasília, DF: SAPS; 2020 mar [acesso 2020 mar 30]. Disponível em: https://www. saude.gov.br/images/pdf/2020/marco/20/20200318ProtocoloManejo-ver002.pdf

5. Yang W, Cao Q, Qin L, et al. Clinical characteristics and imaging manifestations of the 2019 novel coronavirus disease (COVID-19): a multi-center study in Wenzhou city, Zhejiang, China. J Infect. 2020;80(4):388-93. doi: https://doi.org/10.1016/j.jinf.2020.02.016

6. Zhai P, Ding Y, Wu X, et al. The epidemiology, diagnosis and treatment of COVID-19. Int J Antimicrob Agents. 2020;55(5):105955. doi: https://doi.org/10.1016/j. ijantimicag.2020.105955

7. Backer JA, Klinkenberg D, Wallinga J. Incubation period of 2019 novel coronavirus (2019-nCoV) infections among travellers from Wuhan, China, 20-28 January 2020. Euro Surveill. 2020;25(5):2000062. doi: https:// doi.org/10.2807/1560-7917.ES.2020.25.5.2000062 